\title{
Metabolic and cardiovascular responses to liquid and solid test meals
}

\author{
M. Elmukhtar Habas and I. A. Macdonald* \\ School of Biomedical Sciences, University of Nottingham Medical School, Clifton Boulevard, Nottingham NG7 2UH, UK
}

(Received 24 March 1997 - Revised 3 September 1997 - Accepted 25 September 1997)

\begin{abstract}
There is indirect evidence from previous studies that the physiological responses to a liquid test meal may differ from those seen after consumption of a solid meal. The aim of the present study was to determine the metabolic and cardiovascular responses to isoenergetic high-carbohydrate mixed nutrient liquid or solid test meals, providing $2.1 \mathrm{MJ}$ (approximately $70 \%$ of which was from carbohydrate), in eight healthy men following an overnight fast. Metabolic rate increased significantly after both meals $(P<0.0001$, time effect), but the increase was significantly greater after the solid than after the liquid test meal $(0.40$ (SE 0.14$), 0.26$ (SE 0.10$) \mathrm{kJ} / \mathrm{min}$ respectively, $P=0.001)$. The respiratory exchange ratio increased significantly after both the liquid and solid test meals, with no significant differences between them. Forearm blood flow increased significantly after the liquid test meal $(0.70$ (SE 0.33$) \mathrm{ml} / 100 \mathrm{ml}$ per $\min , P<0.0001)$, whilst it decreased after the solid meal $(-0.28$ (SE 0.16$) \mathrm{ml} / 100 \mathrm{ml}$ per min, $P<0.0001$ ). Heart rate increased on both occasions, but the response was significantly greater after the solid meal $(P=0.02)$. There were no significant plasma noradrenaline responses, but there were significantly higher increases in serum insulin and blood glucose following the solid meal. Thus, the physical form of a test meal affects the physiological responses to nutrient ingestion.
\end{abstract}

Metabolic responses: Cardiovascular responses: Liquid/solid test meal

Ingestion of food is associated with an increase in metabolic rate (MR) and changes in cardiovascular variables such as heart rate (HR) and forearm blood flow (FBF). Pure carbohydrate (glucose), and mixed nutrient test drink/meals, have been used to assess these metabolic and cardiovascular responses with varying results (Welle $e t$ al. 1980, 1981; Acheson et al. 1984; Mansell \& Macdonald, 1988; Gallen \& Macdonald, 1990; Segal et al. 1990; Sidery et al. 1990). Robinson \& York (1988) reported a greater MR response to a solid than to a liquid meal following an overnight fast in both smokers and non-smoking healthy subjects. HR and FBF are increased following ingestion of a glucose drink (Sidery et al. 1990), whereas FBF falls after a mixed nutrient solid meal (Sidery et al. 1991, 1993; Sidery \& Macdonald, 1994), although others have reported a tendency for it to increase (Vaz et al. 1995). Similarly, calf blood flow was decreased after solid food (Sidery \& Macdonald, 1994) whereas after a liquid mixed nutrient meal it rose significantly in normal and underfed women (Mansell \& Macdonald, 1988).

The drawback of these previous studies is that they either used a single nutrient (i.e. glucose), did not assess the overall physiological responses, or did not compare liquid and solid test meals directly. The present study was designed to assess whether the use of a liquid test meal would produce different physiological responses to those seen after consumption of a solid meal. As many of the cardiovascular responses are greater after a high-carbohydrate mixed nutrient meal than after a high-fat meal (Sidery \& Macdonald, 1994), the present study compared isoenergetic liquid and solid test meals.

\section{Methods}

Eight healthy men, aged between 16 and 28 years, with mean BMI of 23.5 (SE 1.8$) \mathrm{kg} / \mathrm{m}^{2}$ volunteered to take part in this study, which had Ethical Committee approval. The subjects were asked to do their normal daily activities and to keep to their normal daily food intake before each visit. Each subject attended on two occasions at least $2 \mathrm{~d}$ apart between 08.30 and 09.00 hours after an overnight fast. The study was conducted at a controlled room temperture $\left(25-26^{\circ}\right)$, and subjects wore light clothing. 
During the first $10 \mathrm{~min}$ after arrival, the subject rested supine, and a retrograde venous cannula was inserted into the left hand under local anaesthesia, for arterializedvenous blood sampling (McGuire et al. 1976), and the hand was then placed in a heated-air box for the remainder of the experiment. Saline $(150 \mathrm{mmol} / \mathrm{l})$ was infused to keep the cannula patent. Blood samples $(10 \mathrm{ml})$ were taken every $15 \mathrm{~min}$ for the first $0.5 \mathrm{~h}$ baseline measurements, then every $30 \mathrm{~min}$ following test-meal ingestion for the following $2 \mathrm{~h}$. These samples were used for the subsequent measurements of blood glucose, serum insulin and plasma catecholamine concentrations. MR and respiratory exchange ratio (RER) were assessed by indirect calorimetry, using a ventilated canopy system (Fellows \& Macdonald, 1985). MR was calculated automatically on the basis of the Weir (1949) equation. MR and RER were measured continuously, with interruption of data for $2 \mathrm{~min}$ every $30 \mathrm{~min}$ for measurement of room air and output of results. FBF was measured by venous-occlusion plethysmography (Greenfield $e t$ al. 1963) with a Hg-in-rubber strain gauge (Whitney, 1953) every $15 \mathrm{~min}$. HR and blood pressure were measured by automatic oscillometry (Accutor, Datascope, Paramus, NJ, USA) every $15 \mathrm{~min}$.

Arterialized-venous blood samples were taken for measurement of glucose, insulin and catecholamine concentrations. Blood glucose was measured immediately (YSI 23 AM; Yellow Springs, OH, USA) and the remainder of the sample was separated into two portions. One part was allowed to clot before the serum was removed for storage at $-80^{\circ}$ until measurement of insulin. The other was heparinized and centrifuged and the plasma separated. Plasma $(3 \mathrm{ml})$ was mixed with $75 \mu \mathrm{l}$ ethylene glycol tetraacetic acid-glutathione (antioxidant) before storage at $-80^{\circ}$ for later analysis of plasma adrenaline and noradrenaline concentrations using HPLC with electrochemical detection (Macdonald \& Lake, 1985).

Following $30 \mathrm{~min}$ of baseline measurements, either a high-carbohydrate mixed nutrient liquid meal $(2 \cdot 1 \mathrm{MJ}$, of which $15 \%$ was protein, $18 \%$ fat and $67 \%$ carbohydrate), or a comparable solid meal $(2.1 \mathrm{MJ}$, of which $13 \%$ was protein, $16 \%$ fat and $71 \%$ carbohydrate) was consumed. The liquid meal consisted of semi-skimmed milk $(250 \mathrm{ml})$, glucose polymer $(70 \mathrm{ml}$; Polycal; Nutricia, Bornen, Belgium), a powdered protein ( $45 \mathrm{~g}$; Build-up; Nestlé, Vevey, Switzerland) and double cream $(20 \mathrm{ml})$, while the solid meal consisted of cereal (Special K $(40 \mathrm{~g})$, Kellogg's, Manchester, UK), semi-skimmed milk $(180 \mathrm{ml})$, toasted white bread $(60 \mathrm{~g})$, jam $(30 \mathrm{~g})$, butter $(5 \mathrm{~g})$ and white sugar $(6 \mathrm{~g})$. Both test meals were served at room temperature and completed in $10 \mathrm{~min}$. The order of meal ingestion was random between visits and subjects, and no additional fluid was given after either meal.

\section{Statistical analysis}

Baseline measurements for the two visits were compared by Student's paired $t$ test. Repeated measures two-way ANOVA was used to compare the responses following the two meal forms. To assess the response to each test meal separately, one-way ANOVA was used. A $P$ value of less than 0.05 was taken as significant.

\section{Results}

\section{Metabolic rate and respiratory exchange ratio (Fig. I)}

Baseline MR values were not significantly different at the two visits $(4.85$ (SE 0.27$) \mathrm{kJ} / \mathrm{min}$ before the liquid, and 4.96 (SE 0.26$) \mathrm{kJ} / \mathrm{min}$ before the solid test meal). Following the test meal, MR increased significantly (time effect, $P<0.0001)$. The response was significantly greater after the solid meal $(P=0.001)$, with a mean response of 0.40 (SE 0.14 ) $\mathrm{kJ} / \mathrm{min}$ over the $2 \mathrm{~h}$ after the solid test meal and $0.26(\mathrm{SE} 0.10) \mathrm{kJ} / \mathrm{min}$ after the liquid test meal.

Baseline RER values were not significantly different (0.85 (SE 0.01) for both visits). RER increased similarly after ingestion of the liquid and solid meals (time effect, $P<0.0001$ ), with a mean response of 0.07 (SE 0.02 ) over the $2 \mathrm{~h}$ on both occasions.

\section{Cardiovascular responses (Fig. 2)}

Baseline HR was similar before the liquid and solid meals (64 (SE 4), 60 (SE 2) beats/min respectively). HR increased significantly following the solid and liquid meals (time effect, $P=0.001$ ), and the increase was significantly greater after the solid meal (meal effect, $P=0.02$ ), with mean increases of 6 (SE 2) and 4 (SE 2) beats/min over the $2 \mathrm{~h}$. Baseline diastolic and systolic blood pressure values were not significantly different (116 (SE 3) and 62 (SE 3) $\mathrm{mmHg}$ respectively before the liquid meal, 113 (SE 4) and 62 (SE 2) $\mathrm{mmHg}$ respectively before the solid meal). There were no significant changes in blood pressure after either meal (results not shown). Baseline FBF was slightly higher before the solid than the liquid test meal (2.5 (SE 0.41 ), 2.3 (SE 0.32$) \mathrm{ml} / 100 \mathrm{ml}$ per $\mathrm{min}$ ), although the values were not significantly different. The mean overall FBF responses were significantly different between the solid and the liquid meals $(P<0.0001$, meal effect, ANOVA), with a mean increase of 0.70 (SE $0.33) \mathrm{ml} / 100 \mathrm{ml}$ per min over the $2 \mathrm{~h}$ after the liquid test meal, and a mean fall of -0.28 (SE 0.16$) \mathrm{ml} / 100 \mathrm{ml}$ per min after the solid test meal. Furthermore, using one-way ANOVA to assess the responses following the individual meal types separately showed a significant fall over time after the solid meal $(P<0.0001)$ and a rise after the liquid meal $(P<0.0001)$.

\section{Blood glucose and serum insulin concentrations (Fig. 3)}

Baseline blood glucose concentrations were similar on the two occasions (4.6 (SE 0.11 ) $\mathrm{mmol} / 1$, before the liquid, and 4.6 (SE 0.07 ) $\mathrm{mmol} / \mathrm{l}$ before the solid test meal). Blood glucose concentrations increased significantly after solid and liquid test meal ingestion (time effect, $P<0.0001$ ), and the mean response over $2 \mathrm{~h}$ was greater after the solid test meal (1.59 (SE 0.47) mmol/l) than the liquid test meal (1.14 (SE 0.36) $\mathrm{mmol} / 1, P<0.05$, meal effect). 

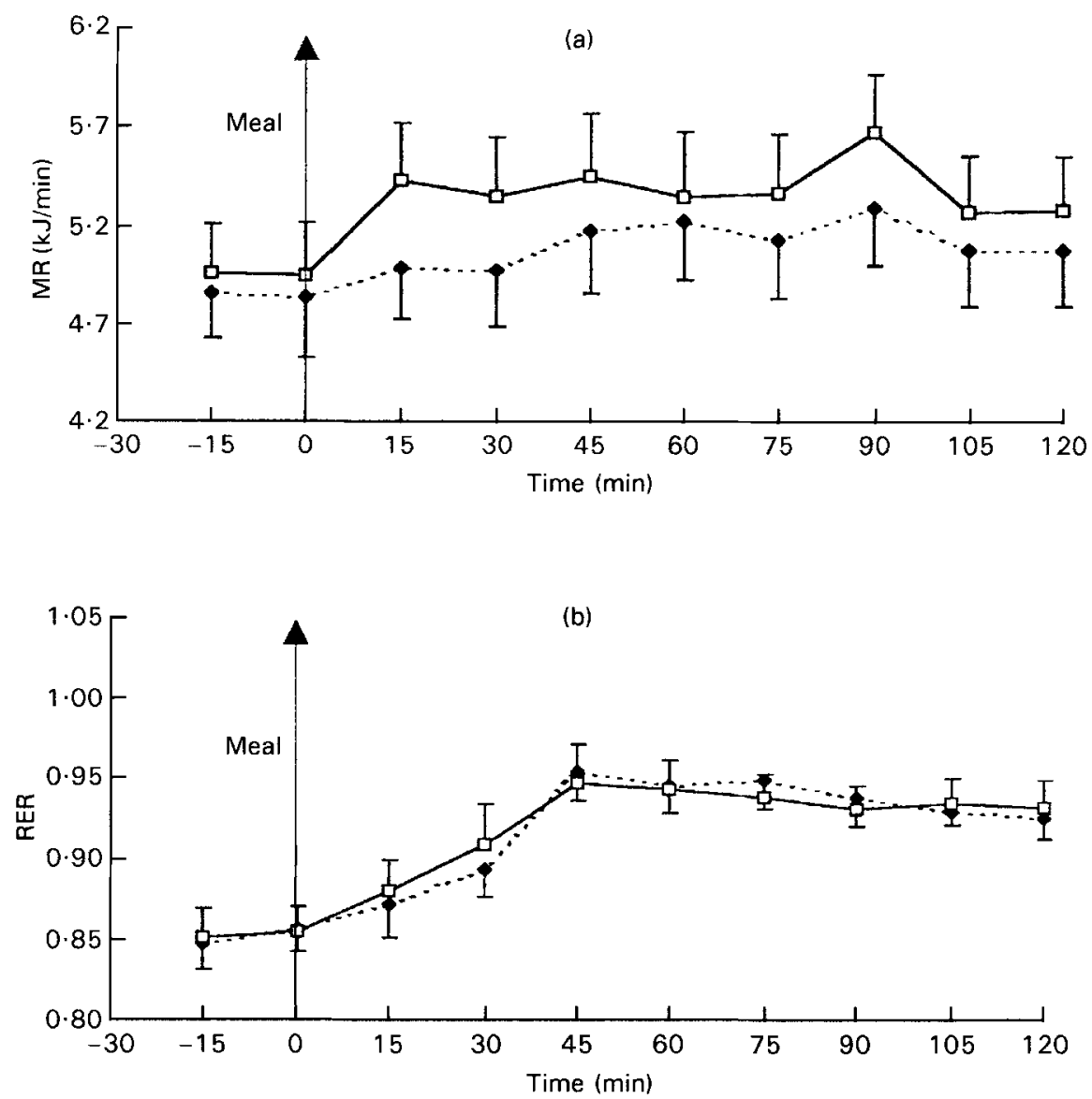

Fig. 1. (a) Metabolic rate (MR) and (b) respiratory exchange ratio (RER) following a high-carbohydrate liquid meal (-- $\rightarrow--)$ and a highcarbohydrate mixed nutrient solid meal $(-\square-)$. Values are means for eight subjects, with their standard errors represented by vertical bars. MR increased significantly after the liquid and solid test meals $(P<0.0001)$, and the increase was significantly greater after the solid meal $(P=0.001)$. RER increased significantly after both test meals $(P<0.0001)$ and the increases were not significantly different.

Baseline serum insulin concentrations were not different at the two visits $(9.7$ (SE 1.5) $\mathrm{mU} / 1$ before the liquid test meal, 10.1 (SE 1.4) $\mathrm{mU} / \mathrm{l}$ before the solid test meal). Serum insulin concentration increased significantly after the liquid and solid test meals (time effect, $P<0.0001$ ), and the mean response over the $2 \mathrm{~h}$ period was significantly higher after the solid test meal $(+61$ (SE 16) $\mathrm{mU} / \mathrm{l})$ than following the liquid test meal (39 (SE 12) $\mathrm{mU} / 1, P<0.001$, meal effect).

\section{Plasma adrenaline and noradrenaline concentrations}

$$
\text { (Fig. 4) }
$$

Baseline plasma adrenaline concentrations $(0.34$ (SE 0.12 ) $\mathrm{nmol} / \mathrm{l}$ before the liquid test meal, 0.31 (SE $0.07) \mathrm{nmol} / 1$ before the solid test meal) and noradrenaline concentrations $(0.99$ (SE 0.10$) \mathrm{nmol} / \mathrm{l}$ before the liquid test meal, 0.99 (SE 0.20) nmol/1 before the solid test meal) were not significantly different. After the solid and liquid test meals, noradrenaline tended to increase (0.24 (SE 0.24) and 0.04 (SE 0.14$) \mathrm{nmol} / 1$ respectively), whereas plasma adrenaline concentrations tended to decrease $(-0.07$ (SE 0.04) and 0.05 (SE 0.07$) \mathrm{nmol} / 1$ respectively). However, these changes were not significant and there were no differences between liquid and solid test meals.

\section{Discussion}

This study assessed the metabolic and cardiovascular responses to either a high-carbohydrate mixed nutrient liquid meal or an isoenergetic solid test meal. MR increases after ingestion of solid meals and drinks, but the responses are affected by meal composition (in particular the macronutrient content), nutritional status, age, race, hormone levels and insulin resistance (Macdonald, 1984; Kinabo \& Durnin, 1990, 1993; Tataranni et al. 1995). Food with a high energy density has a prolonged gastric emptying time (Hunt, 1980), which may delay the MR response, and prolonged measurements would be needed. Furthermore, meals with a high energy content have prolonged effects, requiring long periods of measurements (Reed \& Hill, 1996). Therefore, the present study compared the responses to high-carbohydrate mixed nutrient solid and liquid meals in healthy men, avoiding the effects of sex and body composition. The meal size was restricted to $2 \cdot 1 \mathrm{MJ}$ to limit the duration of the overall responses. It is acknowledged that the $2 \mathrm{~h}$ postprandial period is insufficient to determine the complete responses to the nutrients, but it is likely that the majority of the responses will have been observed in this time. Nevertheless, having observed the 

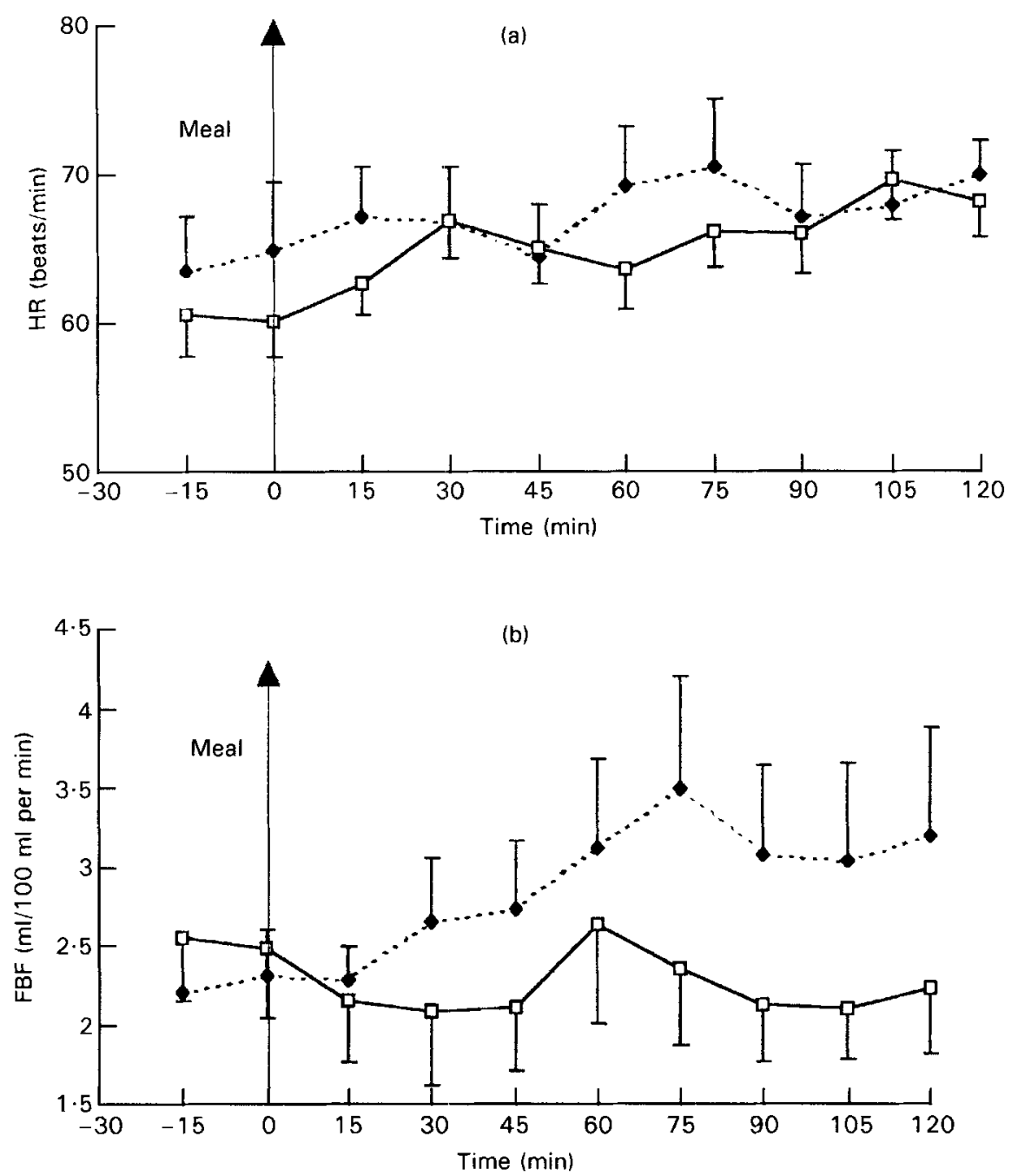

Fig. 2. (a) Heart rate (HR) and (b) forearm blood flow (FBF) following a high-carbohydrate liquid meal (--- - ) and a high-carbohydrate mixed nutrient solid meal (- --$)$. Values are means for eight subjects, with their standard errors represented by vertical bars. HR increased significantly following both the liquid and solid test meals $(P=0.001$, time effect), and the increase was significantly greater after the solid test meal $(P=0.02$, diet effect). FBF responses to the solid and liquid meals were significantly different $(P<0.0001$, meal effect, balanced ANOVA). Following the liquid test meal, FBF increased $(P<0.0001$, one-way ANOVA), while after the solid test meal it decreased $(P<0.0001$, one-way ANOVA).

differences in response to liquid and solid meals in the first $2 \mathrm{~h}$ it would be of interest to conduct further studies over longer time periods to determine the overall magnitude of these differences.

The macronutrient content of the ingested food affects the MR response (Macdonald, 1984; Tappy \& Jequier, 1993). Macdonald (1984) reported that the MR response to glucose $(0.54$ (SE 0.05$) \mathrm{kJ} / \mathrm{min})$ is lower than that to sucrose (i.e. when half of the energy content is from fructose, $0.90($ SE 0.05$) \mathrm{kJ} / \mathrm{min})$. In the present study, the MR response was greater following the solid meal; however, the fructose contents of the solid test meal $(9.7 \mathrm{~g})$ and the liquid test meal $(6.5 \mathrm{~g})$, estimated according to information from the manufacturer, were similar. RER increased by similar amounts on both occasions and the peak RER was less than $0 \cdot 95$, indicating no net lipogenesis with either liquid or solid test meal. The different MR responses to the liquid and solid test meals may be due to differences in gastric emptying, digestibility and absorp- tion. As liquids empty faster than solids from the stomach (Carbonnel et al. 1994), it would be expected that the liquid test meal would have been absorbed more easily and faster than the solid meal, and would then produce higher glycaemic and insulinaemic responses. However, in the present study, MR response, and blood glucose and plasma insulin concentrations were significantly higher after the solid meal. This may be because the liquid test meal used in the present study was hypertonic, leading to a slight delay in gastric emptying (McHugh \& Moran, 1979). We were unable to measure the osmolarity of the drink, but it is likely that it was approximately $500 \mathrm{mosmol} / \mathrm{l}$ as half of the carbohydrate came from Polycal (which has an osmolarity of 900) and the remainder from the disaccharides in the milk and 'Build-up', which were present in a concentration of approximately $100 \mathrm{~g} / 1$ (i.e. approximately isotonic). Another possible factor was that the initial increases in plasma insulin and glucose concentration after the liquid test meal were missed, although this is not supported by the 

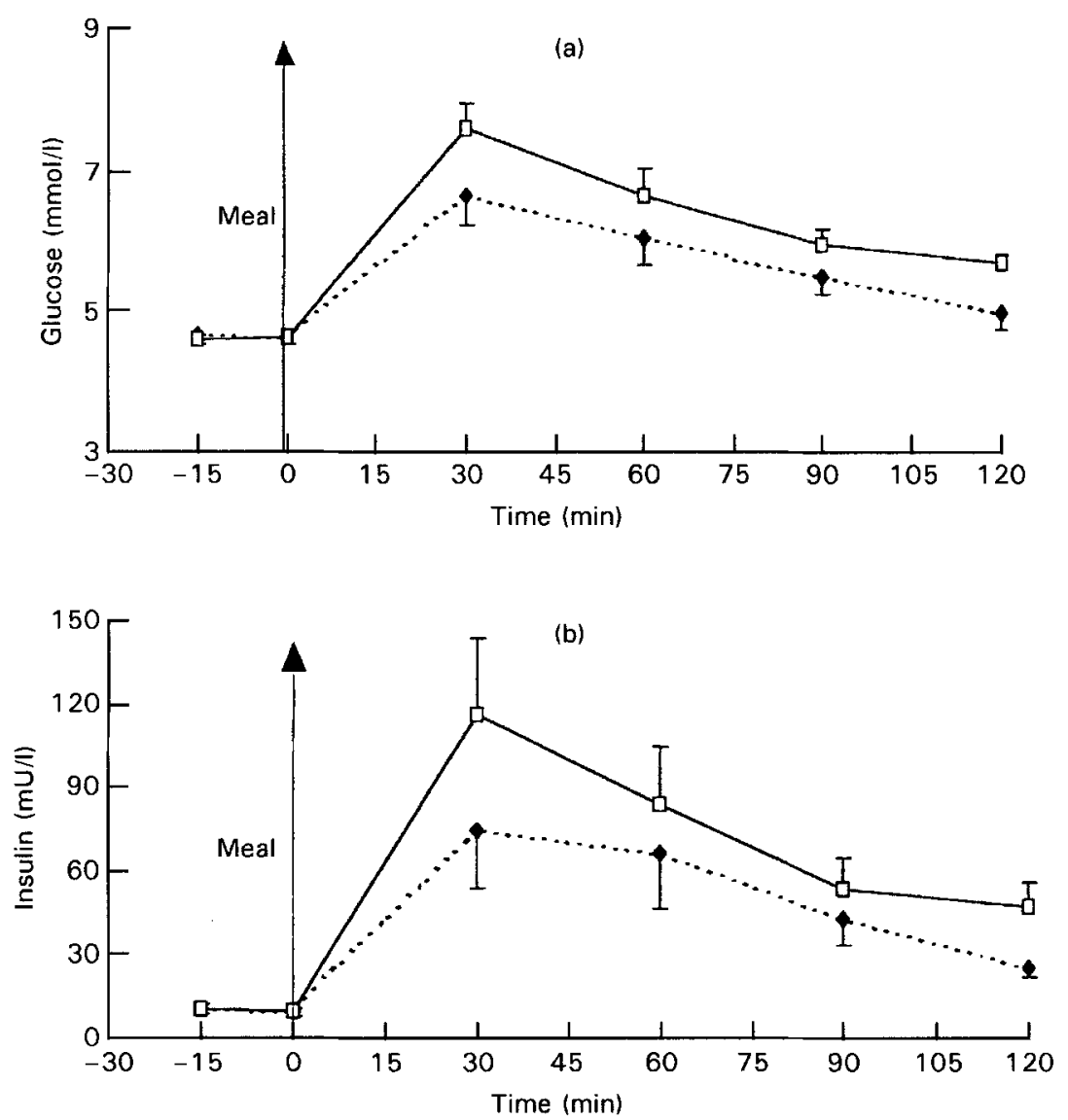

Fig. 3. (a) Blood glucose and (b) serum insulin concentrations following a high-carbohydrate liquid meal (-- $\bullet--)$ and a high-carbohydrate mixed nutrient solid test meal $(-\square-)$. Values are means for eight subjects, with their standard errors represented by vertical bars. Blood glucose concentrations increased after both the liquid and solid meals (time effect, $P<0.0001$ ), and the increase was greater after the solid meal $(P=0.02$, meal effect). Serum insulin concentration increased after the solid and liquid test meals (time effect, $P<0.0001)$, and the response was higher after the solid test meal than after the liquid test meal $(P=0.0001$, diet effect)

literature. Sidery et al. (1990) reported that peak increases of plasma insulin and blood glucose concentrations occurred between 40 and $60 \mathrm{~min}$ after glucose drink ingestion and Gallen \& Macdonald (1990) reported that insulin and glucose concentrations reached a peak between 40 and $60 \mathrm{~min}$ after a mixed nutrient drink. Therefore, from these studies, it is unlikely that an early peak increase in plasma insulin and glucose concentrations was missed in the present study. It is not possible from the present results to explain why the insulin and glucose concentrations were greater after the solid meal, but it is possible that the glucose polymer in the liquid meal was less rapidly digested, i.e. had a lower glycaemic index, than the starch in the bread and cereal. It would be of interest to study this further by assessing rates of gastric emptying and glucose absorption after the two types of test meal, to establish the relationship between nutrient delivery and metabolic and cardiovascular responses.

The increase in MR following glucose ingestion is associated with a rise in plasma noradrenaline and adrenaline concentrations (Welle et al. 1981), which is interpreted as indicating a stimulation of sympathetic nervous system activity. In the present study plasma noradrenaline tended to increase more after the solid test meal than the liquid test meal, whereas adrenaline tended to decrease. However, these changes in catecholamines were not significant, thus there was no evidence of sympathetic nervous system activation. Such sympathetic activation has previously been thought to be responsible for stimulating a facultative thermogenic component of the MR response to nutrient ingestion (Simonsen et al. 1990), in which case there is no evidence of such thermogenesis occurring in the present study. Thus, the greater MR response after the solid meal is likely to be due to the higher obligatory energy cost of digesting the cereal and bread (complex carbohydrate $v$. simple sugars and oligosaccharide), compared with the costs of processing the liquid meal.

In the present study, HR increased following the two meals, supporting previous observations (Sidery et al. 1990; Waaler et al. 1990; Sidery \& Macdonald, 1994). The increase in HR is likely to be associated with an increase in cardiac output (Qamar et al. 1985; Fagan et al. 1986; Sidery et al. 1991; Host et al. 1996), which appears necessary to sustain the higher gut blood flow after a meal (Sidery \& Macdonald, 1994). The mechanism of this cardiac response to food is not established, but it is possible that the increased gut blood flow may have caused transient hypotension, which would lead to either an increase in 

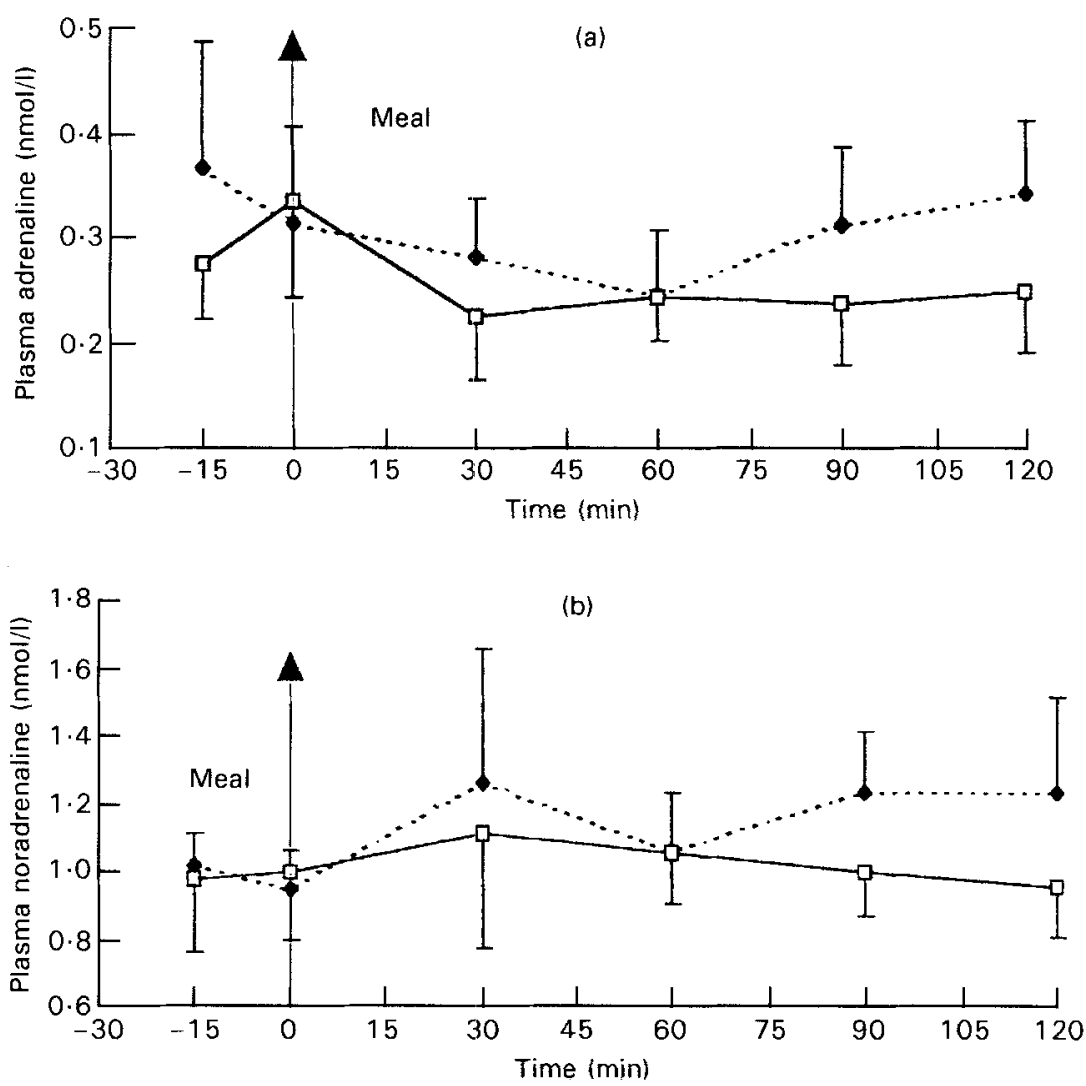

Fig. 4. Plasma (a) adrenaline and (b) noradrenaline concentrations following a high-carbohydrate liquid test meal (-- - -) and a highcarbohydrate mixed nutrient solid test meal (- $\square-)$. Values are means for eight subjects, with their standard errors represented by vertical bars. After the solid and liquid test meals, noradrenaline concentrations tended to increase while plasma adrenaline concentrations tended to decrease, but these changes were not significant.

cardiac sympathetic or a decrease in cardiac parasympathetic nervous activity, thus increasing HR. As there were no differences in the plasma catecholamine levels between the two occasions, it is likely that the greater HR response after the solid meal was due to autonomic nervous effects on the heart. However, plasma insulin increased more after the solid meal in the present study, and insulin is known to increase cardiac muscle contractility and HR, although this has only been observed at a high plasma insulin concentration. This might contribute to the differences in the HR response either indirectly via stimulation of the sympathetic nervous system, or directly due to an effect of insulin on the myocardium (Kearney et al. 1996).

Food ingestion alters regional blood flow, either due to effects of the sympathetic nervous system or by vascular actions of insulin. FBF decreased after ingestion of solid meals in both elderly and young subjects (Sidery $e t$ al. 1993; Sidery \& Macdonald, 1994), whilst after ingestion of a drink, FBF and calf blood flow were increased (Mansell \& Macdonald, 1988; Gallen \& Macdonald, 1990). Consistent with these earlier observations, the present study showed that FBF increased following the liquid test meal, and decreased after the solid test meal. A fall in FBF in the early postprandial period would contribute to the maintenance of blood pressure, by redistributing the cardiac output towards the gastrointestinal tract. Thus, in the present study the response to the solid meal is consistent with this. The absence of any fall in FBF after the liquid test meal is interesting, and rather more difficult to explain. The fact that this was associated with a smaller HR response than after the solid meal, and did not produce a fall in blood pressure, implies that the increase in gastrointestinal blood flow is likely to have been smaller after the liquid test meal. Thus, it is likely that there was a lesser degree of sympathetic vasoconstrictor activity after the liquid test meal, but further studies are needed to examine this possibility, and in particular to assess the influence of meal type of gastrointestinal blood flow responses.

In conclusion, the present study showed that there were significant differences in MR and some cardiovascular responses to liquid and solid test meals. The increased MR response to the solid meal was not associated with any evidence of generalized sympathetic nervous system activation, and appears to be due to obligatory thermogenesis. Consistent with this is the likelihood that the solid meal required a greater intestinal haemodynamic response. Further studies are needed to identify the mechanisms underlying the different responses to solid and liquid food. It is clear from the present study that using liquid test meals may produce misleading physiological responses compared with those seen in normal life with solid food. 


\section{Acknowledgements}

We are most grateful to David Forster, Roger Mullinger, Heather Parkin, Liz Simpson and Julie Taylor for technical assistance. M. E. Habas was supported by a studentship from the Secretary of Education, AL-Jamahiriya, Libya.

\section{References}

Acheson KJ, Schutz Y, Bessard T, Ravussin E, Jequier J \& Flatt JP (1984) Nutritional influence on lipogenesis and thermogenesis after a carbohydrate meal. American Journal of Physiology 246, E62-E70.

Carbonnel F, Lemann M, Rambaud J, Mundler O \& Raymond J (1994) Effect of energy density of a solid-liquid meal on gastric emptying and satiety. American Journal of Clinical Nutrition 60, 307-311.

Fagan TC, Sawyer PR, Gourley LA, Lee JT \& Gaffney TE (1986) Postprandial alteration in haemodynamics and blood pressure in normal subjects. American Journal of Cardiology 58, 636-641.

Fellows IW \& Macdonald IA (1985) An automatic method for the measurement of oxygen consumption and carbon dioxide excretion in man. Clinical Physics and Physiological Measurement 6, 349-355.

Gallen IW \& Macdonald IA (1990) The effects of a $48 \mathrm{~h}$ fast on the physiological responses to food ingestion in normal-weight women. British Journal of Nutrition 63, 53-64.

Greenfield AD, Whitney RJ \& Mowbray JF (1963) Methods for the investigation of peripheral blood flow. British Medical Bulletin 19, 1901-1909.

Host U, Kelbaek H, Rasmusen H, Court-Payen M, Christensen NJ, Pedersen-Bjergaard U \& Lorenzen T (1996) Haemodynamic effects of eating: the role of meal composition. Clinical Science 90, 269-279.

Hunt JN (1980) A possible relation between the regulation of gastric emptying and food intake. American Joumal of Physiology 239, G1-G4.

Kearney MT, Cowley AJ, Stubbs TA, Perry AJ \& Macdonald IA (1996) Central and peripheral haemodynamic responses to high carbohydrate and high fat meals in human cardiac transplant recipients. Clinical Science 90, 473-483.

Kinabo JLD \& Durnin JVGA (1990) Effect of meal frequency on thermic effect of food in women. European Journal of Clinical Nutrition 44, 389-395.

Kinabo JLD \& Durnin JVGA (1993) Thermic effect of food in man: effect of meal composition, and energy content. British Journal of Nutrition 64, 37-44.

Macdonald I (1984) Differences in dietary-induced thermogenesis following the ingestion of various carbohydrates. Annals of Nutrition and Metabolism 28, 226-230.

Macdonald IA \& Lake DM (1985) An improved technique for extracting catecholamines from body fluids. Journal of Neuroscience Methods 13, 239-248.

McHugh P \& Moran TH (1979) Calories and gastric emptying: a regulation capacity with implication for feeding. American Joumal of Physiology 236, R254-R260.

McGuire EAH, Helderman JH, Todin JD, Andres R \& Berman M (1976) Effects of arterial versus venous sampling on the analysis of glucose kinetics in man. Journal of Applied Physiology 41, 565-573.

Mansell PI \& Macdonald IA (1988) The effect of underfeeding on the physiological responses to food in normal weight women. British Journal of Nutrition 60, 39-48.
Qamar MI, Read AE, Skidmore R, Evans JM \& Williamson RCN (1985) Transcutaneous Doppler ultrasound measurements of coeliac axis blood flow in man. British Journal of Surgery 72, 391-393.

Reed GW \& Hill JO (1996) Measuring the thermogenic effect of food. American Journal of Clinical Nutrition 63, 164 169.

Robinson SM \& York DA (1988) Cigarette smoking and the thermic responses to isocaloric meals of varying composition and palatability. European Journal of Clinical Nutrition 42, 551-559.

Segal KR, Chung A, Coronal P, Cruz-Noori A \& Santos R (1992) Reliability of the measurement of postprandial thermogenesis in men of three levels of body fatness. Metabolism: Clinical and Experimental 41, 754-762.

Segal KR, Edano A \& Tomas MB (1990) Thermic effect of a meal over 3 and 6 hours in lean and obese men. Metabolism 39, 985992.

Sidery MB, Cowley AJ \& Macdonald IA (1993) Cardiovascular responses to a high-fat and a high-carbohydrate meal in healthy elderly subjects. Clinical Science 84, 263-270.

Sidery MB, Gallen IW \& Macdonald IA (1990) The initial physiological responses to glucose ingestion in normal subjects are modified by a $3 \mathrm{~d}$ high-fat diet. British Joumal of Nutrition 64, 705-713.

Sidery MB \& Macdonald IA (1994) The effect of meal size on the cardiovascular responses to food ingestion. British Journal of Nutrition 71, 835-848.

Sidery MB, Macdonald IA \& Blackshaw PE (1994) Superior mesenteric artery blood flow and gastric emptying in humans and the differential effects of high fat and high carbohydrate meals. Gut 35, 186-190.

Sidery MB, Macdonald IA, Cowley AJ \& Fullwood LJ (1991) Cardiovascular responses to high fat and high carbohydrate meals in young subjects. American Journal of Physiology 261, H1430-H1436.

Simonson L, Bulow J, Astrup A, Madsen J \& Christensen NJ (1990) Diet-induced changes in subcutaneous adipose tissue blood flow in man: effect of $\beta$-adrenoceptor inhibition. Acta Physiologica Scandinavica 139, 341-346.

Tappy L \& Jequier E (1993) Fructose and dietary thermogenesis. American Journal of Clinical Nutrition 58, S766-S770.

Tataranni PA, Larson DE, Snitker S \& Ravussin E (1995) Thermic effect of food in humans: methods and results from use of a respiratory chamber. American Journal of Clinical Nutrition 61 , 1013-1019.

Vaz M, Turner A, Kingwell B, Chin J, Koff E, Cox H, Jennings G \& Esler M (1995) Postprandial sympatho-adrenal activity: its relation to metabolic and cardiovascular events and to changes in meal frequency. Clinical Science 89, 349-357.

Waaler BA, Eriksen M \& Janbu T (1990) The effect of meal on cardiac output in man at rest and moderate exercise. Acta Physiologica Scandinavica 140, 167-173.

Weir JBDeV (1949) New method for calculating metabolic rate with special reference to protein metabolism. Journal of Physiology 109, 1-9.

Welle S, Lilavivate U \& Campbell RG (1981) Thermic effect of feeding in man: increased plasma norepinephrine levels following glucose but not protein or fat consumption. Metabolism 30, 953-957.

Welle S, Lilavivathana U \& Campbell RG (1980) Increased plasma norepinephrine concentration and metabolic rates following glucose ingestion in man. Metabolism 29, 806-809.

Whitney RJ (1953) Measurement of volume changes in human limbs. Journal of Physiology 121, 1-27. 